\title{
Breast feeding and oral rehydration at home during diarrhoea to prevent dehydration
}

\author{
A S G Faruque, D Mahalanabis, A Islam, S S Hoque, A Hasnat
}

\begin{abstract}
In a case-control study we evaluated the role of maternal behaviour, as reflected in maintenance of breast feeding and the use of oral rehydration therapy (ORT) at home during acute diarrhoea, in preventing dehydration in infants and young children. A systematic 5\% sample was taken of all children aged 1-35 months attending the treatment centre of the International Centre for Diarrhoeal Disease Research, Bangladesh, with acute watery diarrhoea of six days or less between August 1988 and September 1989. There were 285 children with moderate or severe dehydration as cases and 728 with no dehydration as controls in the study.

In a multivariate analysis using a logistic regression model we showed that withdrawal of breast feeding during diarrhoea was associated with a five times higher risk of dehydration compared with continuation of breast feeding during diarrhoea at home. Lack of ORT with either complete formula or a salt and sugar solution at home was associated with $\mathbf{5 7 \%}$ higher risk of dehydration compared with receipt of a reasonable amount of ORT after controlling for several confounders. The confounding variables - that is, lack of maternal education, history of vomiting, high stool frequency, young age and infection with Vibrio cholerae 01-were also shown to be risk factors of dehydration. Health education programmes should promote continued breast feeding and adequate oral rehydration therapy for infants with acute diarrhoea at home.
\end{abstract}

(Arch Dis Child 1992;67:1027-1029)

For the home management of infants and children with diarrhoea, mothers with breast fed children are advised to provide oral rehydration therapy (ORT) and continue breast feeding during an acute attack of illness. ${ }^{1}$ It is expected that this practice will help to protect the breast fed infant from developing a more severe illness. In this paper we assess the role of cessation of breast feeding and lack of ORT during diarrhoea, in the home management of acute watery diarrhoea in infants and children, in increasing the risk of dehydration.

Patients and methods

PATIENT GROUPS

The study was conducted in the Clinical Research Centre of International Centre for Diarrhoeal Disease Research, Bangladesh
(ICDDR, B) located in Dhaka, the capital city. The study population consisted of children aged between 1 and 35 months, presenting with watery diarrhoea for six days or less and evaluated clinically as 'cases', having moderate to severe dehydration, or as 'controls' with no signs of dehydration. A $5 \%$ systematic sample was drawn from all children meeting these criteria seeking care at ICDDR, B during the period of study, August 1988 to September 1989. The case-control design required a sample size of 200 in each study group (with $\alpha=0.05$, power of $90 \%$, and odds ratio of 2$)^{2}$. Only children who had been receiving breast feeding up to the time of onset of diarrhoea were included in the study. Finally, 285 cases and 728 controls were entered in the study.

\section{QUESTIONNAIRE ADMINISTRATION}

Informed consent was obtained from mothers of all patients. We used a field tested, structured, interviewer administered questionnaire. Information was obtained from a clinical examination of each child, from carefully standardised anthropometric measurements, and from a general questionnaire on socioeconomic and demographic characteristics, medical history, and fluid and feeding interventions at home. We assessed dehydration according to simple clinical criteria set to minimise misclassification: none to mild (no clear signs of dehydration, with or without thirst); and moderate to severe dehydration with definite decreased skin elasticity and one or more of four signs-sunken eyes, failure to urinate for six hours, sunken anterior fontanelle, and rapid and weak pulse. Any child who had received any amount of breast milk during this episode of diarrhoea at home was considered to be breast fed. Mothers were asked about use of ORT at home (that is, use of prepackaged complete ORT formula or incomplete salt and sugar solution). The volume of ORT consumed was estimated from comparison with standard containers and expressed in millilitres.

The same questionnaire was given to the study group and to controls. Trained women interviewers interviewed each mother at her child's bedside and the interviewers were monitored for accuracy and completeness of the data. Interviewers had no prior knowledge of the purpose of the study nor were they aware of the classification of children as study cases or controls.

\section{DATA ANALYSIS}

We coded data collected by interview and 
physical examination. Data forms were visually checked for errors as they were collected and transferred to a microcomputer. We validated all data by a series of logical and range checks. Crude odds ratios were computed initially for the association of each factor of interest with dehydration (for example, withdrawal of breast feeding during diarrhoea and amount of ORT consumed at home). Then confounding variables were examined; each crude odds ratio was reevaluated by controlling for each potential confounding variable one at a time by stratified Mantel-Haenszel summary statistics procedure. ${ }^{34}$ Evidence of confounding was examined by comparing the summary estimates of the odds ratio obtained from the stratified analyses with the crude estimates; if the estimate was appreciably altered then the variable was a confounder. The final step of analysis included logistic regression. The approach of modelling was structured. First a basic model was fitted including the variables of interest. Confounders

Table 1 Comparison of cases and controls according to variables of interest and their confounders: univariate analysis

\begin{tabular}{|c|c|c|c|c|}
\hline Variables & $\begin{array}{l}\text { No }(\%) \\
\text { cases } \\
(n=285)\end{array}$ & $\begin{array}{l}\text { No }(\%) \\
\text { controls } \\
(n=728)\end{array}$ & $\begin{array}{l}O R \\
(95 \% C I)\end{array}$ & p Value \\
\hline \multicolumn{5}{|c|}{$\begin{array}{l}\text { Variables of interest } \\
\text { Withdrawal of breast feeding }\end{array}$} \\
\hline $\begin{array}{l}\text { during diarrh } \\
\text { Yes } \\
\text { No }\end{array}$ & $\begin{array}{r}6(2 \cdot 1) \\
279(97 \cdot 9)\end{array}$ & $\begin{array}{c}4(0 \cdot 5) \\
724(99 \cdot 5)\end{array}$ & $\begin{array}{l}3.89(0.96 \text { to } 15.84) \\
1.00\end{array}$ & 0.0576 \\
\hline \multicolumn{5}{|c|}{$\begin{array}{l}\text { Total volume of ORT before } \\
\text { admission }(\mathrm{ml}) t\end{array}$} \\
\hline $\begin{array}{l}\text { None } \\
\leqslant 250 \\
\geqslant 251\end{array}$ & $\begin{array}{r}73(25 \cdot 6) \\
85(29 \cdot 8) \\
127(44 \cdot 6)\end{array}$ & $\begin{array}{l}153(21 \cdot 0) \\
219(30 \cdot 1) \\
356(48 \cdot 9)\end{array}$ & $\begin{array}{l}1.34(0.93 \text { to } 1.92) \\
1.09(0.74 \text { to } 1.60) \\
1.00\end{array}$ & $0 \cdot 2523$ \\
\hline \multicolumn{4}{|c|}{$\begin{array}{l}\text { Maternal education } \\
\text { (years of schooling) }\end{array}$} & \\
\hline $\begin{array}{l}\text { None } \\
1+\end{array}$ & $\begin{array}{l}175(61 \cdot 4) \\
110(38 \cdot 6)\end{array}$ & $\begin{array}{l}351(48 \cdot 2) \\
377(51 \cdot 8)\end{array}$ & $\begin{array}{l}1.71(1.29 \text { to } 2.27) \\
1.00\end{array}$ & $0 \cdot 0002$ \\
\hline \multicolumn{5}{|c|}{ History of vomiting } \\
\hline $\begin{array}{l}\text { Yes } \\
\text { No }\end{array}$ & $\begin{array}{r}253(88 \cdot 8) \\
32(11 \cdot 2)\end{array}$ & $\begin{array}{l}569(78 \cdot 2) \\
159(21 \cdot 8)\end{array}$ & $\begin{array}{l}2.21(1.47 \text { to } 3.33) \\
1.00\end{array}$ & 0.0001 \\
\hline \multicolumn{5}{|c|}{ Maximum stool frequency in a } \\
\hline $\begin{array}{l}\geqslant 11 \\
\leqslant 10\end{array}$ & $\begin{array}{l}127(44 \cdot 6) \\
158(55 \cdot 4)\end{array}$ & $\begin{array}{l}254(34 \cdot 9) \\
474(65 \cdot 1)\end{array}$ & $\begin{array}{l}1.50(1.13 \text { to } 2.00) \\
1.00\end{array}$ & 0.0053 \\
\hline \multicolumn{5}{|c|}{ Age of the child (months) $t$} \\
\hline $\begin{array}{l}1-9 \\
10-35\end{array}$ & $\begin{array}{l}172(60 \cdot 4) \\
113(39 \cdot 6)\end{array}$ & $\begin{array}{l}338(46 \cdot 4) \\
390(53 \cdot 6)\end{array}$ & $\begin{array}{l}1.76(1.32 \text { to } 2.33) \\
1.00\end{array}$ & 0.0001 \\
\hline \multicolumn{5}{|l|}{ Cholera } \\
\hline $\begin{array}{l}\text { Isolated } \\
\text { Not isolated }\end{array}$ & $\begin{array}{r}29(10 \cdot 2) \\
256(89 \cdot 8)\end{array}$ & $\begin{array}{c}19(2 \cdot 6) \\
709(97 \cdot 4)\end{array}$ & $\begin{array}{l}4 \cdot 23(2 \cdot 38 \text { to } 7 \cdot 50) \\
1.00\end{array}$ & $<0.00005$ \\
\hline
\end{tabular}

${ }^{2}$ test.

tThose who had some ORT at home were divided into those who received median volume or less and those who received above the median volume. Age groups were categorised into median age or less and greater than median age.

Table 2 Factors (OR and 95\% CI) associated with the presence of dehydration (dependent variable) in children with acute diarrhoea: multivariate analysis using logistic regression model

\begin{tabular}{|c|c|c|c|c|}
\hline Variables & $\begin{array}{l}\text { Regression } \\
\text { coefficient }\end{array}$ & $S E$ & $\begin{array}{l}\text { Adjusted } O R \\
(95 \%(C I)\end{array}$ & p Value \\
\hline $\begin{array}{l}\text { Variables of interest } \\
\text { Withdrawal of breast feeding during } \\
\text { diarrhoea at home }\end{array}$ & $1 \cdot 654$ & 0.684 & $5 \cdot 23(1.37$ to $19 \cdot 99)$ & 0.016 \\
\hline $\begin{array}{l}\text { ORT at home } \\
\text { None } \\
\leqslant 250 \mathrm{ml}\end{array}$ & $\begin{array}{l}0 \cdot 4505 \\
0 \cdot 1657\end{array}$ & $\begin{array}{l}0 \cdot 192 \\
0 \cdot 175\end{array}$ & $\begin{array}{l}1.57(1.08 \text { to } 2.29) \\
1.18(0.84 \text { to } 1.66)\end{array}$ & $\begin{array}{l}0.019 \\
0.343\end{array}$ \\
\hline $\begin{array}{l}\text { Confounding variables } \\
\text { Illiterate mother } \\
\text { History of vomiting } \\
\text { High stool frequency in any } 24 \text { hour }\end{array}$ & $\begin{array}{l}0.4630 \\
0.7177\end{array}$ & $\begin{array}{l}0 \cdot 150 \\
0 \cdot 217\end{array}$ & $\begin{array}{l}1.59(1.18 \text { to } 2.13) \\
2.05(1.34 \text { to } 3.14)\end{array}$ & $\begin{array}{r}0.002 \\
<0.001\end{array}$ \\
\hline $\begin{array}{l}\text { period }(11+) \\
\text { Young age (1-9 months) } \\
\text { Cholera (positive) }\end{array}$ & $\begin{array}{l}0.3774 \\
0.5929 \\
1.648\end{array}$ & $\begin{array}{l}0 \cdot 156 \\
0 \cdot 152 \\
0 \cdot 321\end{array}$ & $\begin{array}{l}1.46(1.07 \text { to } 1.98) \\
1.81(1.34 \text { to } 2.44) \\
5.20(2.77 \text { to } 9.75)\end{array}$ & $\begin{array}{r}0.015 \\
<0 \cdot 001 \\
<0.001\end{array}$ \\
\hline
\end{tabular}

identified from the stratified analyses were then entered into the model individually. Adjusted odds ratios (OR) and $95 \%$ confidence intervals (CI) of variables of interest were estimated while controlling for a number of confounders simultaneously, with state of dehydration as the dependent variable. ${ }^{5}$

\section{Results}

The data from the two study groups are shown in table 1. Withdrawal of breast feeding - a rare event in both groups-was more common in cases than in controls $(p=0.0576)$. Absence of ORT at home was more common among cases but did not reach statistical significance. Mothers of the children in the study group were more illiterate than those of controls $(p=0 \cdot 0002)$. A history of vomiting $(p=0.0001)$ and high frequency of stool $(p=0.0053)$ were more frequently reported by the study group than controls. Children among the cases were younger than the controls $(p=0 \cdot 0001)$. Cholera was more common among the cases than controls $(\mathrm{p}=<0 \cdot 00005)$.

Table 2 shows the results of multivariate analyses by logistic regression. The adjusted OR and $95 \% \mathrm{CI}$ of each variable of interest were computed. The mother's behaviour in withdrawing breast feeding during the infant's diarrhoea was associated with five times higher risk of dehydration compared with continuation of breast feeding during diarrhoea at home $(\mathrm{OR}=5 \cdot 23,95 \% \mathrm{CI}=1 \cdot 37$ to $19 \cdot 99, \mathrm{p}=0 \cdot 016)$; lack of ORT at home was associated with $57 \%$ higher risk of dehydration $(\mathrm{OR}=1.57,95 \%$ $\mathrm{CI}=1.08$ to $2 \cdot 29, \mathrm{p}=0.019)$ compared with receiving good amount of ORT after controlling for lack of maternal education (none $v 1+$ years of schooling), history of vomiting, high stool frequency $(11+$ in any 24 hours), young age, and infection with Vibrio cholerae 01 . It should be noted that, although the odds ratio is large for cessation of breast feeding, the attributable risk for this community is small, because cessation of breast feeding during diarrhoea is rare. However, the population attributable risk for no use of ORT is substantial. The confounding variables adjusted for were also significantly associated with dehydration.

\section{Discussion}

The widely recommended practice of continued breast feeding during diarrhoea provides much needed nutrition to a breast fed child. Breast milk should also provide extra fluid during diarrhoea which may assist in preventing dehydration. The present study provides evidence, probably for the first time, that cessation of breast feeding during diarrhoea at home is an added risk for development of dehydration in breast fed children. This is plausible because, when breast feeding is continued during diarrhoea, the amount of breast milk intake is not much reduced. ${ }^{6}$ Breast milk provides free water because of its low osmotic property; it has also been shown that continued breast feeding during diarrhoea reduces diarrhoeal frequency, duration, and ORT requirement. ${ }^{7}$ In healthy, exclu- 
sively breast fed, infants breast milk has been shown to provide enough free water even in a hot environment. ${ }^{8}$ It is, therefore, plausible that continued breast feeding during diarrhoea may protect a child from dehydration.

Is the cessation of breast feeding the mother's decision or the child's inability to feed? It may be a consequence of severe diarrhoea which is associated with dehydration. In the multivariate analysis, the OR for cessation of breast feeding has been adjusted for indicators of severity of dehydration like high stool frequency and for the presence of cholera and vomiting. In addition, the strength of the association would also suggest a cause and effect relationship. Cessation of breast feeding during diarrhoea was an uncommon event among this population. This cannot therefore, be a major contributor to the development of dehydration among infants and children in Bangladesh. In a study of rural Bangladesh, withdrawal of breast feeding was shown to be associated with severe disease, defined as a patient having altered consciousness or high fever or with severe dehydration, or resulting in death in hospital or after discharge. ${ }^{9}$

The usefulness of ORT in correcting dehydration once it has developed has been extensively documented. ${ }^{1}$ It is also believed that early use of ORT may prevent dehydration. Surprisingly little evidence has been provided in the literature to support this belief. Our study provides evidence that home use of a convincing amount of ORT reduces the risk of dehydration by about $39 \%$, although the amount of ORT fluid used at home may not have been adequate. The perceived severity of diarrhoea may lead to increased use of ORT at home by knowledgeable mothers and, therefore, the degree of protection demonstrated is likely to be an underestimate. In the multivariate analysis the OR was adjusted for indicators of severity such as high stool frequency and cholera. The presence of vomiting may alter ORT behaviour at home, so adjustment has also been made for this.

In interpreting the results of this study there are potential sources of bias that should be considered. To avoid misclassification, dehydration was so defined that only the children with unequivocal signs of dehydration were included as cases. Severely malnourished children could have been misdiagnosed as cases; this should occur no differently for those who received ORT or were breast fed at home. Furthermore, through the careful training of physicians involved in the study and the systematic evaluation of the accuracy of our data, misclassification of dehydration status was avoided. Selection of controls from the same reporting area as the study group should have minimised selection bias. Neither the mothers nor the interviewers were aware of the group status of any child during the study. The interviewers were not informed of the hypothesis being tested. The name of ICDDR, B and quality care provided free of charge for decades, together with lack of a comparable health facility in the area, minimised referral bias.

The results of our study have implications for the treatment of diarrhoea in the home. Although breast feeding is usually maintained during diarrhoea in Bangladesh, the consumption of other foods is often reduced. ${ }^{10}$ In areas where either ORT is not given in adequate amounts or the practice of withdrawal of breast feeding during diarrhoea is common, a number of severe or fatal cases can be anticipated. In a nationwide study in rural India, ${ }^{11}$ among 3590 mothers who were breast feeding their children at the time of the last episode of diarrhoea, $17 \%$ of the mothers stated that breast feeding should be stopped during diarrhoea; interestingly only $1 \%$ of them actually stopped breast feeding during the diarrhoeal episode. An analysis of respondents who believed that breast feeding should be stopped during diarrhoea revealed that literate mothers formed a significantly higher proportion holding attitudes that breast feeding should stop compared with illiterate mothers ( $25 \% v 17 \%)$. In some areas of India as many as $58 \%$ of mothers stated that breast feeding should be stopped during diarrhoea in a child.

Our data suggest a need for cost effective health education programmes to promote continued breast feeding and adequate ORT for infants with acute diarrhoea at home. Such programmes directed to mothers in the community should minimise the risk of severe dehydration in these patients.

This research was supported by the World Health Organisation and the International Centre for Diarrhoeal Disease Research, Bangladesh (ICDDR, B). The ICDDR, B is supported by countries and agencies which share its concern for the health problems of developing countries. Current donors include: the aid agencies of the Governments of Australia, Bangladesh, Belgium, Canada, Denmark, France, Japan, the Netherlands,
Norway, Saudi Arabia, Sweden, Switzerland, the United Kingdom, and the United States; international organisations Kingdom, and the United States; international organisations including the United Nations Development Programme, the
United Nations Children's Fund, and the World Health Organisation; and private foundations including the Ford Organisation; and private foundations
Foundation and the Sasakawa Foundation.

We would like to thank Dr J R Hamilton, McGill University, Montreal for reviewing the paper. We acknowledge the assistance of Mr Simon Cousens of the London School of Hygiene and Tropical Medicine in data analysis. We thank the clinicians of the ICDDR, B's Clinical Research Centre for their valuable support in the clinical assessment and care of the patients. We acknowledge Mr M A Khan and other interviewers for their excellent team work in data collection.

1 World Health Organisation. Programme for control of diarrhoeal diseases. A manual for the treatment of acute diarrhoeal diseases. A manual for the treatment of acute diarrhoea: for use by physic

2 Schlesselman JJ. Case-control studies. New York: Oxford University Press, 1982.

3 Mantel N, Haenszel W. Statistical aspects of the analysis of data from retrospective studies of disease. $\mathcal{F}$ Natl Cancer Inst 1959;22:719-48.

4 Breslow NE, Day NE. Statistical methods in cancer research. Vol 1. The analysis of case-control studies. (IARC scientific publication No 32.) Lyon: International Agency for Research on Cancer, 1980.

5 Mauritsen R. EGRET software program. Seattle, WA: Statistics and Epidemiology Research Corporation, 1986.

6 Hoyle B, Yunus M, Chen LC. Breast-feeding and food intake among children with acute diarrhoeal disease. Am $\mathcal{f}$ Clin among children with atr 1980;33:2365-71.

7 Khin-Maung-U, Nyunt-Nyunt-Wai, Myo-Khin, Mu-MuKhin, Tin-U, Thane-Toe. Effect on clinical outcome of breast feeding during acute diarrhoea. BMF 1985;290: 587-9.

8 Brown KH, Kanashiro HCD, Aguila RD, Romana GLD, Black RE. Milk consumption and hydration status of exclusively breast-fed infants in a warm climate. $\mathcal{F}$ Pediatr 1986;108:677-80.

9 Clemens JD, Harris JR, Sack DA, et al. Discontinuation of breast-feeding during episodes of diarrhoea in rural Bangladeshi children. Trans R Soc Trop Med Hyg 1988;82: 779-83. $10 \mathrm{Khan} M \dot{M}$, Ahmad K. Withdrawal of food during diarrhoea:
major mechanism of malnutrition following diarrhoea in Bangladesh children. $\mathcal{F}$ Trop Pediatr 1986;32:57-61.

11 Rohde JE, Viswanathan H. Diarrhoea in rural India. $A$ nation-wide study of mothers and practitioners. All India summary. (Incorporating orient paperbacks.) New Delhi: Vision Books Pvt Ltd, 1990:49-51. 